\title{
Evaluation model of regional water supply capacity based on AHP- CRITIC method
}

\author{
Lingjie Zhou ${ }^{1, a}$ \\ ${ }^{1}$ North China Electric Power University, Baoding, Hebei, China \\ a446048694@qq.com
}

Keywords: AHP-CRITIC method, Water resource, Evaluation

\begin{abstract}
This paper aims at evaluating the ability of a region to provide clean water to meet the needs of its population by establishing a multi-index comprehensive evaluation model. According to the UN water scarcity map, Australia was selected as the representative region to be evaluated by the model in order to analyze the reason of its water shortage.
\end{abstract}

\section{Introduction}

Evaluation model involves 5 first-grade indexes: natural water source and ecological factors, technological advances related to water resources, freshwater withdrawal, social factors, pollution, and 13 second-grade indexes covering several aspects like environment, society, economic and so on. There are two parts in the evaluation model: the first part is to use AHP to give weight to indexes subjectively by using the Critic Weighting Method to give weight objectively. In order to ensure proper subjectivity professional opinion while taking full advantage of objectivity, we applied linear weighting method to calculate the eclectic combined weight; the second part is to comprehensively evaluate the standardized data with the weights. The evaluation results of the model, which accurately reflect the water supply capability of the regions indicates that six continents' water supply capability can be listed from low to high as follows: 0.3415 for African, 0.4188 for Oceania, 0.4977 for Europe, 0.5481 for Asia, 0.5542 for North America, and 0.7500 for South America (on 1.000-point scale), which is quite an accordant result with the actual situation.

Water resource is not only an important natural resource, but also a basic environmental element, which can not be replaced in the sustainable development of social economy. [1] The establishment of a complete water resources evaluation model benefits in monitoring water consumption and pollution, improving access to higher quality water resources and realizing the sustainable development of water resources. To establish a perfect evaluation model, it is necessary to decide on choosing a comprehensive set of representative index system.

Referencing the various kinds of existing water resource evaluation model[2][3], along with feasibility analysis on the subdivision of indexes of nature and society. through the choice of these indexes, Table 1 can be set up to show the multi-level water supply capability evaluation system: 
Table 1. Evaluation index system of a region's ability to provide water

\begin{tabular}{|c|c|c|}
\hline the target layer & the first-grade index & the second-grade index \\
\hline \multirow{11}{*}{$\begin{array}{l}\text { the ability of a region to } \\
\text { provide clean water to } \\
\text { meet the needs of its } \\
\text { population }\end{array}$} & \multirow{3}{*}{$\begin{array}{c}\text { natural water source and } \\
\text { ecological factors }\end{array}$} & renewable freshwater \\
\hline & & percentage of arid area \\
\hline & & reservoir capacity \\
\hline & technological advances & the using of \\
\hline & related to water resources & $\begin{array}{l}\text { unconventional water } \\
\text { resources }\end{array}$ \\
\hline & \multirow{4}{*}{ freshwater withdrawal } & industrial use \\
\hline & & agricultural use \\
\hline & & residential use \\
\hline & & population density \\
\hline & social factors & per capita GNI \\
\hline & nollution & coverage rate of sanitation \\
\hline
\end{tabular}

A proper mathematical model is expected to be established, which can effectively combine the indexes above to evaluate the capability of supplying water of a region.

\section{Assumption}

The whole model is established basing on the following assumption:

1. Take no indexes into consideration except those we have chosen.

2. The indexes is representative enough.

3. The weight given by the sample data is accurate enough.

\section{The Model}

\section{Determining the weight of each index}

The process of calculating the weight is as follows:

Step 1. Weighting by AHP. To minimize the difficult of comparison cause by the difference of traits of the factors, the AHP uses the relative scale to measure the index two two to compare the result and calculate the weight. If comparison of a certain grade's $N$ indexes $C_{1}, C_{2}, \ldots, C_{n}$ 's impact of on the upper grade of index $O$ is needed, choose a proper scale from $1 \sim 9$ to each two indexes $C_{i}$ and $C_{j}$ to reflect the impact. The final result can be illustrated by the following matrix:

$$
A=\left(a_{i j}\right)_{n \times n}, a_{i j}>0, a_{j i}=\frac{1}{a_{i j}}
$$

The comparison matrix was calculated:

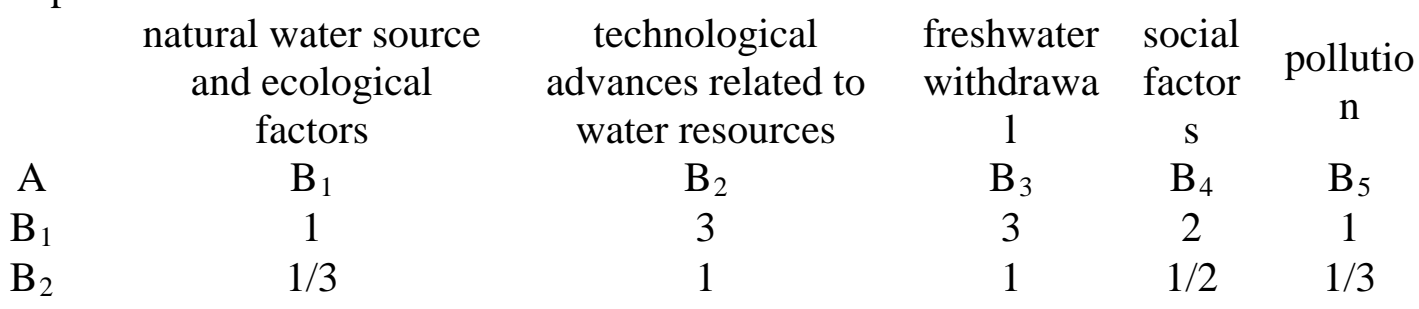

It can be calculated that the maximum eigen value of the matrix $\lambda=5.0133$, along with the corresponding eigen vector $\mathrm{W}=[0.6306,0.1984,0.1984,0.3549,0.6306]$, after which we can calculate that the consistency index $\mathrm{CI}=0.0033$, and the consistency rate $\mathrm{CR}=\mathrm{CI} / 1.12=0.0030<$ 0.1 , validating its consistency. Therefore, this eigen vector can be used as the weight of each firstgrade index after normalization. Similarly we may determine the second-grade indexes' weight.

Step 2. Weighting by Critic Weighting Method. Critic Weighting Method is a simple and effective method of objective weighting. In the Critic Weighting Method, we assume that $\mathrm{P}_{\mathrm{j}}$ 
indicates j-th second grade index's information content under any first grade index, which can be calculated by the following formula:

$$
P_{j}=\sigma_{j} \sum_{t=1}^{4}\left(1-r_{t j}\right)
$$

Determining objective weights of indexes requires sample data as a reference, so we collected data related to water supply capability of the six continents from the Internet. After proper process, the data collected can be used as indexes that satisfy the demands:

Table 2.Evaluation index value of a region's ability to provide water

\begin{tabular}{lcccccc}
\hline $\begin{array}{l}\text { Continent } \\
\text { Index value }\end{array}$ & Africa & $\begin{array}{c}\text { North and } \\
\text { central } \\
\text { America }\end{array}$ & $\begin{array}{c}\text { South } \\
\text { America }\end{array}$ & Asia & $\begin{array}{c}\text { Europ } \\
\text { e }\end{array}$ & $\begin{array}{c}\text { Oceani } \\
\text { a }\end{array}$ \\
\hline $\begin{array}{c}\text { renewable water per } \\
\text { capita }\left(\mathrm{km}^{3} / \mathrm{p}\right)\end{array}$ & 5.39 & 13.34 & 43.60 & 3.46 & 10.59 & 45.91 \\
$\begin{array}{c}\text { percentage of arid } \\
\text { area (\%) }\end{array}$ & 66 & 34 & 31 & 46 & 32 & 75 \\
$\begin{array}{c}\text { Dam capacity per } \\
\left.\text { capita (million m } \mathrm{m}^{3} / \mathrm{p}\right)\end{array}$ & $\begin{array}{c}1086.6 \\
0\end{array}$ & 14767.49 & 2518.69 & $\begin{array}{c}2030.4 \\
6\end{array}$ & 523.53 & $\begin{array}{c}3361.3 \\
2\end{array}$
\end{tabular}

Step 3. Combined weight. Let $\alpha_{i}$ be the weight calculated by AHP, and $\beta_{i}$ be the weight calculated by Critic Weighting Method, and the linear weighting formula is:

$$
\psi_{i}=\delta \alpha_{i}+(1-\delta) \beta_{i}, i=1,2, \ldots, 13
$$

In order to balance objectivity and subjectivity, we let $\delta=0.5$. According to formula (1), the weights are calculated as follows:

Table 3.Weight of each Index

\begin{tabular}{cccc}
\hline the first-grade index & Weight & the second-grade index & Weight \\
\hline $\begin{array}{c}\text { natural water source and } \\
\text { ecological factors }\end{array}$ & 0.3133 & renewable freshwater & 0.4608 \\
\hline & percentage of arid area & 0.5392 \\
\hline $\begin{array}{c}\text { technological advances } \\
\text { related to water resources }\end{array}$ & 0.0986 & $\begin{array}{c}\text { reservoir capacity } \\
\text { the using of } \\
\text { unconventional water } \\
\text { resources }\end{array}$ & 0.4658 \\
\hline
\end{tabular}

\section{Conclusion and Discussion}

The model successfully evaluated water supply capability of the six continents, and the result shows a acceptable agreement with the actual situation, validating the reliability of the model. By applying the model to Australia, it is discovered that evaporation, surface water shortage are the main environmental drivers of water shortage, and uneven distribution of population, water deficient areas of population density are the main social drivers, which lead to scarce water supply.

\section{References}

[1]Wang Pin, Zhang Jinyu, Yang Hunan. Discussion on the present situation and development of water resources assessment [J]. Water Resources \& Hydropower of Northeast China, 2002, 20(7):34-35.

[2]Zhang Liping, Zhu Zhonglin, Deng Liangji. Present Situation of and Problems in Water Resource Evaluation Indicator Systems in China [J]. Department of Resources and Environment, 2004, 21(4):5-0. 
[3]Cheng Mingling, Yuan Yi, Zhou Minghua. Study on the Evaluation Index System of Water Resources of Zhejiang Province [J]. Bulletin of Science and Technology 2009, 25(2):167-173. 